\title{
PRODUCCIÓN DE BIODIESEL A PARTIR DE ACEITE CRUDO DE PALMA (Elaeis guineensis), PARA SU USO COMO FASE CONTINUA EN FLUIDOS DE PERFORACIÓN
}

\section{Rubén D. Vega M., Rocielys del V. Muñoz D., Yexander J. Chettick S.}

\section{RESUMEN}

El uso de aceites como fase continua en fluidos de perforación conllevó al desarrollo de un fluido a partir de aceite crudo de palma (Elaeis guineensis). Para ello, fue necesario aplicar un proceso de transesterificación para obtener un éster o biodiésel. Al ser caracterizado, este cumplió con la norma ASTM B100, excepto por la viscosidad cinemática (6,38 cSt), la cual superó el valor máximo regulado. Asimismo, presentó un espectro IR típico de un biodiesel de palma lo que confirmó la calidad del biodiesel obtenido aplicando metanólisis ácida y básica. Seguidamente, se formuló un fluido de perforación con una densidad de $1437,92 \mathrm{~kg} / \mathrm{m}^{3}$ y se sometió a un proceso de envejecimiento dinámico a $121,1^{\circ} \mathrm{C}\left(250^{\circ} \mathrm{F}\right)$ y $1,38 \mathrm{MPa}(200 \mathrm{psi})$. El fluido resultante demostró tener mejores propiedades físicas que fluidos de igual densidad como el Vassa y el gasoil. Finalmente, se estudió su comportamiento al reducir e incrementar la temperatura en $27,7^{\circ} \mathrm{C}$ con respecto a la temperatura de envejecimiento inicial, presentando un funcionamiento ideal a las menores temperaturas $\left(93,3\right.$ y $\left.121,1^{\circ} \mathrm{C}\right)$, pero una degradación térmica a $148,8^{\circ} \mathrm{C}$, lo que lo convierte en no funcional a esa temperatura.

Palabras Clave: Fase Continua, Transesterificación, Biodiésel, Propiedades Físicas, Degradación Térmica.

DOI: $10.23881 /$ idupbo.021.1-10i 